\title{
Development and Transformation Strategies of Banking Industry under the Background of Fintech
}

\author{
Fujia $\operatorname{Sun}^{1}$ \\ ${ }^{1}$ China Agricultural University Beijing, China
}

\begin{abstract}
In recent years, emerging technologies such as blockchain, big data, and artificial intelligence have developed rapidly and been applied in the financial field, which has caused earth-shaking changes in the overall structure of the financial industry and exerted a profound impact on the banking industry in particular. This paper starts with an overview of financial technology, analyzes the opportunities and challenges faced by the banking industry in the context of financial technology, and makes relevant recommendations on the coordinated development and transformation of the banking industry.
\end{abstract}

\section{Introduction}

With the rapid development of the Internet and information technology, the integration of finance and technology has become an unstoppable development trend. While financial technology has injected vitality into the traditional banking industry, it has also brought a huge impact. Therefore, it is of considerable research value to analyze the opportunities and challenges faced by the banking industry under the background of financial technology and find the entry point for the transformation and development of the banking industry.

\section{Overview of Fintech}

\subsection{Definition of Fintech}

Fintech is not originally an academic term, but originally derived from the combination of the terms "finance" and "technology". At present, there is no unified definition of Fintech. The representative definition comes from the 2016 International Financial Stability Board (FSB): Fintech refers to the financial innovation brought by technology, that is, Fintech takes technology (including big data, cloud computing, artificial intelligence, blockchain and other new Technology) as the core driving force, aims to improve the efficiency and benefits of financial services, and realizes the deep integration of finance and technology by innovating financial supply and services.

\subsection{The development stage of Fintech}

The industry divides the history of technology-enabled finance into three phases. First, the electronic business phase from the late 1980 s to the early 1990 s, Financial institutions use IT technology to build information systems, and transfer traditional manual operations based on pen and paper to computers and their databases. Second, the Internet finance stage at the beginning of the $21 \mathrm{st}$ century, the rise of "Internet thinking" has enabled Internet and other professional technology companies to enter the financial industry, build online business platforms, realize information sharing, and change traditional channels. As a result, innovative businesses such as online banking, mobile payment, $\mathrm{P} 2 \mathrm{P}$, and crowd-funding emerge at the historic moment. The third is the stage of smart finance since 2018. The emergence of new technologies such as big data, blockchain, and artificial intelligence has caused profound changes in the traditional financial service model, giving birth to more scenario innovations and more wisdom Financial services.

\subsection{The development trend of Fintech}

With the in-depth integration of finance and technology, Fintech presents the following development trends. On the one hand, in order to improve the efficiency of financial services, and increase industry competitiveness, the demand of traditional licensed financial institutions for the application of technologies such as big data analysis and artificial intelligence has led to the gradual commoditization of technologies, for example, from offline outlets to telephone banking, automated teller machines, to online banking and mobile payment. On the other hand, technology-driven companies such as the Internet and e-commerce have entered the financial industry, which has led to the alienation of financial institutions. For example, Apple has set foot in the fields of payment and consumer credit, and launched the contactless digital payment service called Apple Pay. 


\section{Opportunities and challenges faced by the banking industry in the context of Fintech}

With the rapid development and spread of financial technology, the banking industry is faced with the impact of technological changes on the industry's competitive landscape and its own business development. Fintech has brought both opportunities and challenges to the development of the banking industry.

\subsection{Development opportunities}

\subsubsection{Operating costs reduction}

On the one hand, Fintech can reduce management costs. First, in terms of labor costs, OCR technology and RPA technology can achieve the goal of replacing manual work with machines, thereby the number of commercial banks' outlets and the number of tellers in outlets has been decreasing year by year. Second, in terms of information costs, the development of big data technology enables banks to obtain market, customer, and competitor information more comprehensively and quickly, reducing the cost of information collection in the past.

On the other hand, Fintech can also reduce compliance costs. First, in terms of KYC, face to face, voice print and fingerprint recognition technology to replace manual verification of identity authentication. Second, in terms of transaction monitoring, stream computing technology and risk monitoring models provide real-time and accurate monitoring of anti-fraud and anti-money laundering. Third, in terms of data reporting, distributed database systems help banks better respond to regulatory changes by reducing the cost of data storage and analysis.

\subsubsection{Improve service efficiency}

With the development of Fintech, blockchain technology is widely used in traditional business fields such as electronic bills, payment and settlement, and its features such as trustlessness and decentralization enable banks to eliminate unnecessary intermediates in the transaction process. In addition, banks adopt big data, cloud computing and other technologies to realize data sharing, meet the diverse needs of customers, and improve service efficiency in areas such as accurately measuring risks.

\subsubsection{Enhance customer acquisition ability}

Fintech has opened up new ways to reach customers. The development of Fintech has broken through the limitations of geography and distance. Online services are no longer restricted by space, and the marginal cost of new customers is almost zero, which also enables banks to serve more remote areas and low-frequency demand customers, which improves the bank's inclusive customer acquisition capabilities. For example, according to the financial report data of Ping An Bank in the past two years, it can be found that under the background of financial technology, Ping An Bank has achieved remarkable results in developing online customers. Figure 1 shows the changing trend of monthly customer activity of Ping An Pocket Bank APP in the past two years.

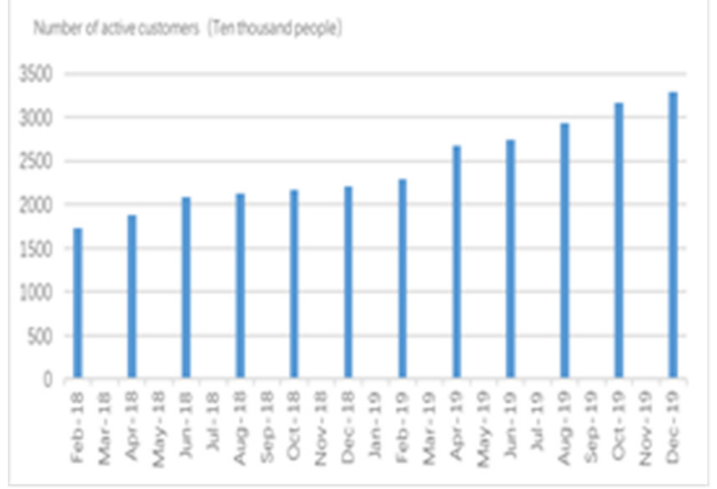

Figure I. Trend chart of monthly active devices of Ping An Pocket Bank APP

As can be seen from the figure, from 2018 to 2019, the number of branches of Ping An Bank decreased by 1.3\%, but the number of customers increased by nearly 1.5 times, and the monthly activity of Ping An Pocket Bank users increased by nearly 2 times.

\subsection{Development challenges}

\subsubsection{The phenomenon of "disintermediation" leads to shrinking of the banking market}

"Disintermediation" refers to the fact that the borrower and the lender bypass the commercial bank to directly conduct financing, which greatly weakens the bank's intermediary function. In recent years, the trend of "disintermediation" has become more apparent. On the one hand, for individuals, third-party payment platforms such as Alipay and WeChat Pay are gradually replacing traditional bank payment methods. On the other hand, for enterprises, the higher deposit interest rate and small loans with "small amount and short term" offered by Fintech companies are more attractive for investors to transfer from commercial banks to Fintech companies.

\subsubsection{Impact on the bank's business model}

The operating model of traditional commercial banks has been unable to adapt to the market demand in the era of Fintech. Banks should combine science and technology, change the traditional offline business mode, and strive to realize the mode of "scene at the front, intelligent at the middle and cloud at the back". For example, one is that banks should launch intelligent robots at business outlets to speed up service response speed and accuracy. The second is to learn to use big data, model optimization and machine learning to carry out intelligent decision-making, and gradually reduce the reliance on human expert experience judgment. The third is to focus on using cloud computing technology to shorten the entire business process and reduce transaction costs. 


\subsubsection{Bank credit function is weakened}

In the era of Fintech, the customer data information owned by financial technology companies is becoming more and more comprehensive, and they have established their own data information database. On the one hand, blockchain technology has higher security because it cannot be tampered with, and is expected to revolutionize the speed of liquidation. On the other hand, artificial intelligence can imitate the learning and analysis of the human brain, thereby making customer portraits more efficient and accurate. Therefore, the development of financial technology has reduced the bank's advantages in information collection or analysis and processing, and has greatly weakened the bank's original credit function as an information center.

\section{Suggestions on the development and transformation of the banking industry}

Technology has become the core driving force for the transformation and development of the banking industry at this stage. The banking industry must conform to the development trend of the deep integration of finance and technology to achieve the goal of transformation and development.

\subsection{Independent development of Fintech}

In terms of customer acquisition promotion, the first is to strengthen the construction of electronic channels and mobile services. Banks should create their own websites, APPs and other online platforms, and pay attention to their construction and promotion to meet the needs of customers in the Internet era. The second is the shift of service focus from offline to online, and the transformation of physical outlets to experience stores, providing complex and personalized services, and establishing a distinctive brand image of the bank. The third is to promote the seamless connection of services across channels, achieve consistency in products and services across channels, and create differentiated advantages in integrated services.

In terms of business innovation, it is necessary to develop Fintech and use its advantages to improve data mining and technical analysis capabilities. The first is to build a digital bank based on blockchain technology to shorten the payment and settlement process with lower cost, higher efficiency and safety. The second is to build an information bank based on big data to achieve more precise customer segmentation and reduce financing and lending risks. The third is to build a smart bank based on artificial intelligence, analyze customer needs in depth, and form a more popular inclusive market with customized financial services.

In terms of operation management, the first is to introduce emerging IT operation models such as agile development and continuous delivery, and use flexible, high-speed, and low-cost processing and storage technologies to update information systems. The second is to realize the front, middle and back office automation, and build a flexible mechanism and a flat management structure that can quickly respond to changes in market and regulatory needs. The third is to establish and improve a talent pool for technological innovation. Talents are an important resource for the development of financial technology. Banks should focus on the cultivation of talents and establish a reasonable and effective incentive mechanism to retain and attract new talents.

\subsection{Cooperation with financial technology companies}

On the one hand, although banks should increase investment in technology research and development, technology research and development is neither their main business nor their areas of expertise. Even if they develop it, it is difficult to achieve the same level as technologydriven financial technology companies. On the other hand, banks are restricted in technology research and development due to risk avoidance, regulatory boundaries, and responsibilities, while financial technology companies are very flexible in researching new technologies and applying innovative concepts. Therefore, through cooperative, banks can use advanced technologies from financial technology companies and take advantage of their free and flexible R\&D advantages to launch innovative products.

In addition, there are also large gaps in scientific and technological talents in the banking industry. Table 1 shows the comparison of accounting personnel of commercial banks and Fintech enterprises in 2018. It can be seen that the number of scientific and technological personnel in state-owned commercial banks and jointstock banks is far behind Ant Financial Services and Tenxen Fintech in terms of the total number of employees. In particular, fewer of the technical staff of traditional commercial banks are involved in Fintech innovation. Emerging Fintech companies such as Ant Financial and Tencent Fintech have a large proportion of scientific and technological talents in research and development and technological innovation.

TABLEI. A comparison of accounting personnel in commercial banks and Fintech enterprises in 2018

\begin{tabular}{|c|c|c|}
\hline \multirow{2}{*}{$\begin{array}{c}\text { Bank or Technology } \\
\text { Company }\end{array}$} & \multicolumn{2}{|c|}{$\begin{array}{c}\text { Statistics of Scientific and Technical } \\
\text { Personnel }\end{array}$} \\
\cline { 2 - 3 } & Quantity & The proportion \\
\hline ICBC & 15276 & 3.40 \\
\hline ABC & 6190 & 1.31 \\
\hline BOC & 6967 & 2.54 \\
\hline CMBC & 2003 & 2.69 \\
\hline SPDB & 2402 & 4.53 \\
\hline $\begin{array}{c}\text { Ant Financial } \\
\text { Services Group }\end{array}$ & 63000 & 63.00 \\
\hline $\begin{array}{c}\text { Tencent Financial } \\
\text { Technology }\end{array}$ & 38775 & 64.62 \\
\hline
\end{tabular}

Even if banks select talents for scientific research and training, due to the lack of cutting-edge textbook knowledge framework systems such as financial technology, it is difficult for practitioners to break out of their inherent thinking mode and industry operation awareness. Therefore, banks can cooperate with financial technology companies and exchange regularly, or they can 
take advantage of the other side's scientific research personnel to serve as technical consultants to study the thinking and operating methods of financial technology companies.

\section{Conclusion}

With the deepening of the integration of finance and technology, the development of Fintech has produced a profound impact on the traditional banking industry. On the one hand, Fintech has brought development opportunities to the banking industry. The application of emerging technologies can reduce operating costs, improve service efficiency and enhance customer acquisition capabilities. On the other hand, technological development has also brought challenges to the banking industry, such as the impact of business models, weakened credit functions, disintermediation and shrinking markets. In order to better respond to the impact of financial technology, the traditional banking industry should actively develop financial technology, increase investment appropriately, and strengthen cooperation with financial technology companies to achieve mutual benefit.

\section{References}

1. Cao Xianliang. (2020) Research on the mechanism of the impact of financial technology on the efficiency of commercial banks. J. China Prices, Commun., 379(11): 72-75.

2. Lai Ru. (2019) Research on the development of financial technology and banking J. Science \& Technology Economics Guide, Commun., 27(07): 212-213.

3. Wang Ping. (2020) Impact of Fintech on Traditional Commercial Banks: Challenges and Opportunities J. Market Journal, Commun., 33(08):146-147.

4. Shen Yuan, Chen Weijing. (2017) Analysis on the Impact of Fintech on Commercial Banks J. Time Financial, Commun., 30: 84-85.

5. Wu Chuqiao. (2020) The Impact of Fintech on Commercial Banks and Countermeasures J. Chinese and Foreign Entrepreneurs, Commun., 632(06): 56.

6. Liu Yongheng. (2020) Commercial banks' transformation and development strategy under the background of financial technology J. Northern Finance, Commun., 10: 77-79+95. 